OPEN ACCESS

Edited by:

Alberto Gullo,

Centro Neurolesi Bonino Pulejo

(IRCCS), Italy

Reviewed by:

Ajesh Maharaj,

University of KwaZulu-Natal,

South Africa

Clementina López-Medina

Reina Sofía Hospital, Spain

*Correspondence: Eric Toussirot

etoussirot@chu-besancon.fr orcid.org/0000-0002-6228-1464

Specialty section:

This article was submitted to Rheumatology,

a section of the journal

Frontiers in Medicine

Received: 23 September 2021

Accepted: 19 October 2021

Published: 08 November 2021

Citation:

Toussirot E (2021) The Risk of

Cardiovascular Diseases in Axial Spondyloarthritis. Current Insights.

Front. Med. 8:782150

doi: 10.3389/fmed.2021.782150

\section{The Risk of Cardiovascular Diseases in Axial Spondyloarthritis. Current Insights}

\author{
Eric Toussirot ${ }^{1,2,3,4 *}$ \\ ${ }^{1}$ INSERM CIC-1431 Centre Investigation Clinique, CHU de Besançon, Besançon, France, ${ }^{2}$ Rhumatologie, CHU de \\ Besançon, Besançon, France, ${ }^{3}$ Département de Thérapeutique, Université de Bourgogne Franche-Comté, Besançon, \\ France, ${ }^{4}$ INSERM UMR1098 Relations Hôte Greffon Tumeurs, ingénierie cellulaire et génique, Université de Bourgogne \\ Franche-Comté, Besançon, France
}

There is an increased cardiovascular (CV) risk in axial spondyloarthritis (axSpA), leading to increased CV mortality and morbidity in these patients. The factors that may explain this enhanced CV risk in axSpA are multiple, including traditional CV risk factors such as smoking, but also the inflammatory process and probably the use of non-steroidal anti-inflammatory drugs (NSAIDs). The CV involvement of axSpA may be detected at an early and pre-clinical stage, using non-invasive techniques. While NSAIDs play a deleterious role in the CV risk of axSpA, TNF inhibitors seem to have a beneficial impact, but this remains to be demonstrated in specific clinical studies. More data are needed to determine the potential effects of $\mathrm{IL}-17$ inhibitors on the CV risk of axSpA. CV comorbidity has been mainly assessed in the radiographic form of axSpA, while limited data are available in patients with the non-radiographic form. The current management of axSpA must consider this CV comorbidity according to the EULAR recommendations. Rheumatologists play a determinant role in the detection of $\mathrm{CV}$ risk and current management of these patients is focused on the control of disease activity, suppression of inflammation, screening for and management of traditional CV risk factors, as well as the restriction of NSAID use.

Keywords: ankylosing spondylitis, spondyloarthritis, cardiovascular risk, cardiovascular risk factors, atherosclerosis

\section{INTRODUCTION}

Axial spondyloarthritis (axSpA) refers to an interrelated group of inflammatory rheumatic diseases (IRD) that primarily affect the axial skeleton (1). Radiographic changes of the sacroiliac joints are a hallmark of the disease, and enable the diagnosis of ankylosing spondylitis (AS) according to the modified New York criteria (2). The Assessment of SpondyloArthritis international Society (ASAS) has developed a set of criteria for the recognition of patients with early axSpA that includes evidence of sacroiliitis visible by magnetic resonance imaging (MRI), chronic back pain, HLA-B27 positivity and other non-articular symptoms (3). These criteria distinguish the radiographic ( $\mathrm{r}$ axSpA, formely AS) and non-radiographic (nr-axSpA) forms of axSpA, according to the presence or absence of structural changes of the sacroiliac joints on pelvic X-rays. When the clinical features predominate in peripheral joints, $\mathrm{SpA}$ may be classified as a peripheral form (pSpA). 
Besides extra-articular manifestations (psoriasis, acute anterior uveitis and inflammatory bowel diseases), additional comorbidities are described in axSpA, including cardiovascular (CV) involvement $(4,5)$. Rheumatoid arthritis (RA) is another IRD for which there is ample evidence of an increased CV risk (6). In parallel, there is a cumulating body of evidence that axSpA may promote the development of atherosclerosis, $\mathrm{CV}$ manifestations and complications including myocardial infarction and/or stroke $(4,5,7)$.

In this review, we analyze the evidence for CV mortality and morbidity in axSpA, as well as the traditional CV risk factors that may participate in the increased CV risk seen in axSpA patients.

\section{MORTALITY IN axSpA}

Mortality in axSpA is mostly described in AS, with limited information in $\mathrm{nr}-\mathrm{axSpA}$, due to the recent individualization of this subgroup $(4,8)$. This excess mortality in AS has been previously related to radiation treatment, a therapeutic option that was used until the seventies (9). However, studies on the mortality rate in AS are not concordant. In an analysis from the Mayo Clinic (Rochester, Minnesota USA) in 1979, there was no difference in mortality between male patients with AS and the general male population (10). On the contrary, other studies have reported an excess of mortality in AS, with a standardized mortality ratio (SMR) ranging from 1.6 to 1.9 (1113) (Table 1). These studies took radiation therapy into account, and the increased mortality persisted even in patients who did not receive this treatment. A relationship between mortality in AS and disease duration and severity was also reported (13). A study from Norway confirmed these results (14): in a population of 677 AS patients followed in a reference center for a 34 year period, the SMR was increased in male patients [1.63; 95\% confidence interval (CI): 1.29-1.97] compared to a control group. Circulatory disease was the most frequent cause of death (40\%) and the factors linked to decreased survival were delayed diagnosis, an increase in acute phase reactants, work disability and the absence of NSAID use. In a series of 2,154 patients with AS from Hong Kong, the SMR was calculated to be 3.07 [2.64-3.5], and 1.89 [1.61-2.13] after adjustment for age. The most frequent cause of death was infection, ahead of $\mathrm{CV}$ complications (15). In nationwide cohorts of AS patients from Scandinavian countries, the (age- and sex-) adjusted hazard ratio (HR) for death among AS patients was 1.60 [1.44-1.77] with increased mortality in both male and female patients. A low level of education and general comorbidities (including CV diseases) were identified as predictors of death (16). In a Spanish study analyzing CV mortality and CV events at 5 years in different IRD, AS was found to have the highest risk of a first CV event [HR: 4.6 (1.32-15.99)], but without increased CV deaths (17). Finally, a recent meta-analysis concluded that $\mathrm{CV}$ mortality in AS was increased, with a relative risk (RR) of 1.46 [1.15-1.86] (18).

\section{CARDIOVASCULAR MORBIDITY IN axSpA}

Mortality in axSpA (AS) is consistently related to CV diseases and complications. In a large American administrative database comparing CV diseases in different IRD including 1,843 patients with AS, the prevalence ratios for ischemic heart disease, cerebrovascular disease and congestive heart failure ranged between 1.2 and 1.8 (19). In a retrospective cohort study conducted in Canada, and including 8,616 patients with AS, the prevalence of $\mathrm{CV}$ and cerebrovascular diseases increased with age, but age- and sex-stratified prevalence ratios were highest in younger people, ranging from 1.25 for cerebrovascular disease to 1.37 for ischemic heart disease (20). These results were in line with recent data from a Swedish cohort followed from 2006 to 2012, where the standardized incidence ratios (SIRs) for acute coronary syndrome and stroke were higher in patients compared to the general population (4.3 and 5.4/1,000 person years compared to 3.2 and 4.7, respectively) (21). On the contrary, the study by Brophy et al. (22) did not find an increased prevalence of acute myocardial infarction or stroke among patients with AS compared to those without AS. Different meta-analyses have examined the risk of CV diseases and/or complications in patients with axSpA. Mathieu et al performed such an analysis in 2011, and updated it in 2015. In the first metaanalysis, based on 11 studies, there was no significant increase in myocardial infarction or stroke in AS (23), while in the updated meta-analysis, which included 6 additional studies, there was a significant increase in both $\mathrm{CV}$ complications [myocardial infarction: odds ratio (OR) 1.6 (1.32-1.93) and stroke: OR 1.5 (1.39-1.62), respectively] (24). The more recent meta-analysis of 16 studies by Kim et al also reported a significantly higher risk of myocardial infarction in AS [RR: 1.49 (1.34-1.66) (18). The COMOSPA study was devoted to comorbidity analysis in $\mathrm{SpA}$, including patients with axial or peripheral SpA (ax-SpA: 89\%; pSpA: 56\%]. The prevalence of ischemic heart disease and cerebrovascular disease was $2.7 \%$ [2.2-3.2] and $1.3 \%$ [0.91.7], respectively (25). Finally, results form a cross-sectional study in Spain were recently published. That study examined the CV burden in patients with $\mathrm{r}$-axSpA and nr-axSpA by means of ultrasound assessment. The results indicated that the atherosclerotic involvement was similar between these 2 forms (26).

\section{CARDIOVASCULAR RISK FACTORS IN axSpA}

There are several possible explanations for the higher $\mathrm{CV}$ risk in axSpA: inflammation is a well-recognized factor for accelerated atherosclerosis in different IRD, including axSpA, while traditional $\mathrm{CV}$ risk factors may also play a role. In addition, specific axSpA-related cardiac manifestations (aortic insufficiency and atrioventricular conduction disturbances) may also contribute to the enhanced CV risk.

\section{Smoking}

It is now established that cigarette smoking has a negative influence on axSpA activity and severity (27). In the French DESIR cohort of patients with early SpA, smoking was associated with early disease onset, high disease activity, increased axial structural damage on X-ray, and poor quality of life (28). In the COMOSPA study, the prevalence of smoking in SpA ranged from 6 to $44 \%$, depending on the countries (25). 
TABLE 1 | Standardized mortality ratio (SMR) or hazard ratio in patients with radiographic axial spondyloarthritis.

\begin{tabular}{|c|c|c|c|c|}
\hline References & Number of patients & Country & Duration of follow-up (years) & SMR/HR \\
\hline Smith and Doll (9) & 14,111 & United Kingdom & 16 & SMR: 1.66 \\
\hline Radford et al. (11) & 836 & United Kingdom & 13 & SMR: 1.6 (men) \\
\hline Karprove et al. (12) & 151 & Canada & 27 & SMR1.93 (men) \\
\hline Lethinen et al. (13) & 398 & Finland & 25.7 & SMR:1.5 \\
\hline Bakland et al. (14) & 677 & Norway & 33 & SMR: 1.63 (men) \\
\hline Mok et al. (15) & 2,154 & China & 9 & SMR: 1.88 \\
\hline Exarchou et al. (16) & 8,600 & Sweden & 6 & HR: 1.6 \\
\hline
\end{tabular}

\section{Hypertension}

It is estimated that the prevalence of hypertension is higher in axSpA than would be expected in the general population (4). In a small series of patients with AS $(N=20), 20 \%$ had hypertension (29). In the COMOSPA study, the proportion was higher (33.5\%), especially in northern European countries (25). Continuous use of NSAIDs may impact on the development of hypertension: in a prospective longitudinal $\mathrm{r}$-axSpA cohort, continuous NSAID use was associated with a $12 \%$ increased risk for the development of incident hypertension compared to patients with non-continuous use or no NSAID use (30).

\section{Diabetes and Metabolic Syndrome}

In the COMOSPA study, the prevalence of diabetes was $8.8 \%$ (25). A high frequency of metabolic syndrome according to the NCEP-ATP III criteria was found in a limited series of patients with axSpA ( $N=24$; frequency: 45.8 vs. $10.9 \%$ in the controls) (31).

\section{Obesity}

A recent study found that patients with axSpA may present with increased weight: in that study, obesity was found in $22 \%$ of patients and overweight in $37 \%$, according to the $\mathrm{WHO}$ criteria (32). However, body composition studies did not find an excess of fat mass, but an increased lean mass (33).

\section{Dyslipidemia}

The relationships between lipid parameters and IRD are complex. Indeed, inflammation has a wide range of effects on lipids, both quantitatively and qualitatively. Under the pressure of inflammation, both LDL and HDL cholesterol tend to decrease, but with an imbalanced atherogenic index (total cholesterol/HDL cholesterol) (34). In parallel, lipids are subject to qualitative changes, toward a pro-atherogenic profile for HDL cholesterol, and oxidation for the LDL fraction (35). All these modifications promote an increased CV risk in IRD (36). In axSpA, similar lipid changes are described. The prevalence ratio of dyslipidemia was 1.2 in a large series of patients with AS (19). In more recent series, HDL cholesterol was found to be decreased, with an elevated atherogenic index $(37,38)$. In addition, the levels of $\mathrm{HDL}$ cholesterol and apolipoprotein-A have been associated with CV complications in axSpA [HR: 3.67 (1.47-9.06) and 1.89 (1.023.54)] (39).

\section{PRECLINICAL ATHEROSCLEROSIS IN axSpA}

Non-invasive techniques may be used for the identification of early arterial wall changes in IRD. Ultrasonography of carotid arteries is the most widely used method, giving results on intima media thickness (IMT), pulse wave velocity (PWV) and flow mediated dilatation (FMD). It is a valid method for the identification of pre-clinical atherosclerosis with the capacity to predict future CV disease and complications (7). This method has been extensively used in RA, showing impaired endothelial function as well as arterial wall changes (40). Similar results were obtained in patients with axSpA. In two meta-analyses, IMT was reported to be increased in patients with AS $(23,41)$. A third recent meta-analysis of 35 studies reported an increased IMT and PWV and a decreased FMD in patients with AS, indicative of a higher risk of subclinical atherosclerosis (42). Carotid plaques are frequently observed in axSpA compared to a control population (29.7 vs. $9.4 \%$ ) and the presence of such plaques correlated with acute phase reactants but not IMT (43). Endothelial dysfunction as evaluated by FMD was impaired in a series of 43 patients with axSpA compared to 40 healthy controls (44). In the cross-sectional study from Spain, there was no difference in the prevalence of carotid plaques or in carotid IMT between patients with $\mathrm{r}$-axSpA and those with nr-axSpA. In addition, when using the $\mathrm{CV}$ risk assessment model (SCORE), the percentage of patients classified in the very high risk category was comparable between the 2 groups, indicating that the CV burden was similar in nr-axSpA and r-axSpA (26).

\section{THE EFFECT OF TREATMENT ON CARDIOVASCULAR RISK IN axSpA}

The CV impact of the treatments that are routinely used in axSpA may be bidirectional, i.e., beneficial and/or detrimental. Indeed, since atherosclerosis should be seen as an inflammatory disease, and the CV risk in IRD is largely influenced by inflammation, controlling inflammation would have a favorable impact on this comorbidity. In RA, it is well-established that methotrexate (MTX) and TNF $\alpha$ inhibitors (TNFi) positively influence the CV risk (45).

\section{NSAIDs}

It is well-recognized that all the NSAIDs have a negative impact on CV risk, contributing to an excess of CV complications (46). Among the different NSAID class, coxib and diclofenac were 


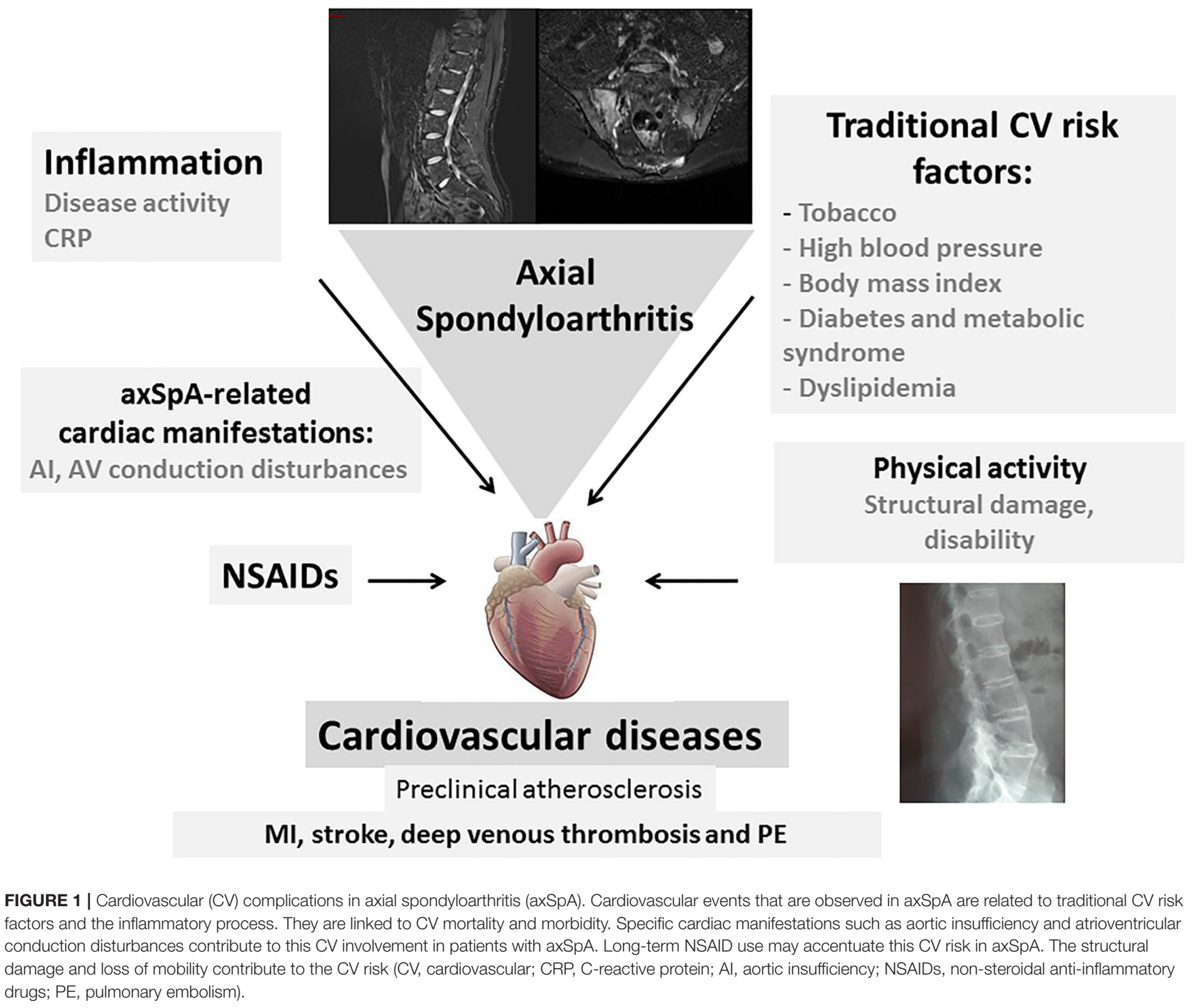

associated with the higher risk of major vascular events while this risk was less with naproxen (46). NSAIDs are used as first line of treatment in axSpA, but not continuously, according to different recommendations. However, the CV risk induced by NSAIDs in axSpA remains controversial. Indeed, in a Canadian study on the mortality of AS, the lack of NSAID intake was one factor associated with increased CV mortality (47). The same result was found in a Norwegian study showing an excess of death from vascular disease. One of the factors associated with reduced life expectancy was the lack of NSAID use [OR: 4.53; (1.75-10.77)] (14). To explain these results, it was suggested that NSAIDs may partially control inflammation, and thus, in patients not using NSAIDs, atherosclerosis may accelerate. However, these results may reflect a selection bias by proposing NSAIDs only to patients without $\mathrm{CV}$ risk factors.

\section{Conventional Synthetic DMARDs}

Sulfasalazine (SLZ) is used in selective cases of SpA, with limited efficacy in the peripheral form. Since SLZ has an aspirin moiety, it has been suggested that this drug may have a protective CV effect. In a Taiwanese population-based retrospective study, the use of SLZ provided a protective effect against CV diseases in patients with AS [HR: 0.65 (0.43-0.99)] (48).

\section{Biological DMARDs}

In RA, TNFi result in a $20-50 \%$ reduction in CV risk (49). There are numerous studies demonstrating that TNFi may reduce subclinical inflammation in axSpA. Results are not universally concordant, but overall, TNFi may favorably impact IMT and endothelial dysfunction, with a stabilizing effect on the atheromatous plaque (50-52). In the systematic review by Tam et al. it was concluded that TNFi are effective in AS in preventing or even reversing the progression of IMT in patients responding to treatment. Pulse wave velocity was reduced or unchanged under TNFi treatment, while aortic augmentation index was also largely unchanged (53). Lipid parameters may fluctuate under TNFi. In axSpA, the atherogenic index did not change under infliximab, while it improved under etanercept $(54,55)$. In a 
prospective study of patients with AS receiving a TNFi, we did not observe significant changes in insulin parameters (HOMA-IR index) (56).

The experience with IL-17 inhibitors (IL-17i) in axSpA is shorter compared to the use of TNFi, with no specific study examining the CV risk. It is considered that IL-17A may have deleterious effect on the arterial wall and cardiac cells, with potentially pro-atherogenic properties (57). In the secukinumab and ixekizumab development programs, there were no reports of increased CV events $(58,59)$. Similarly, the long term followup of patients with psoriasis under secukinumab did not reveal a specific CV signal or an increase in major adverse CV events (MACE) or CV mortality $(60,61)$. Major CV events were not increased with long term use of ixekizumab in a pooled analysis from 21 clinical trials in patients with psoriasis, psoriatic arthritis (PsA) and axSpA (62).

\section{Targeted Synthetic DMARDs}

Janus kinase inhibitors (JAKi) (tofacitinib, upadacitinib, filgotinib) are currently in development in $\operatorname{axSpA}$, but upadacitinib has recently been approved for the treatment of axSpA. During the phase 3 clinical trials, there was no safety signal regarding $\mathrm{CV}$ events with JAKi in patients with axSpA (63). In a systematic review and meta-analysis of the CV effects of JAKi in patients with RA in randomized controlled trials, there was no evidence of a significant change in CV risk in the short term (64). In a post hoc analysis from the RA, psoriasis and PsA development programs and observational studies, the incidence rates for deep vein thrombosis (DVT), pulmonary embolism (PE) and venous thromboembolism (VTE) were similar between tofacitinib doses ( 5 vs. $10 \mathrm{mg}$ twice daily) but generally higher in patients with CV or VTE risk factors (65). However, concerns have recently emerged regarding the risk of thrombosis under tofacitinib, leading to warnings by competent authorities. The ORAL surveillance trial analyzed the safety of tofacitinib $(5 \mathrm{mg}$ and $10 \mathrm{mg}$ twice daily) vs. a TNFi in subjects with RA aged 50 years or older and with at least one additional CV risk factor. The primary endpoints in this trial were non-inferiority of tofacitinib compared to TNFi in regard to MACE and malignancies (excluding non-melanoma skin cancer). Final analysis of ORAL surveillance showed that the non-inferiority criteria were not met for the primary comparison of the combined tofacitinib doses vs. TNFi [HR for MACE: 1.33 (0.91-1.94); HR for malignancies: $1.48(1.04-2.09)]^{1}$. The conclusion is that there was a higher risk of MACE and malignancies (excluding non-melanoma skin cancer) with tofacitinib as compared to TNFi in patients with RA. Following these results, healthcare professionals were advised to keep considering the benefits and risks of tofacitinib when deciding to prescribe and continue patients on the drug ${ }^{2}$.

\section{DISCUSSION}

There is compelling evidence that there is an increased CV risk in $\operatorname{axSpA}$, and that it represents a major comorbidity deserving

\footnotetext{
${ }^{1}$ https://clinicaltrials.gov: NCT02092467.

${ }^{2}$ https://www.pfizer.com/news/press-release/press-release-detail/pfizer-sharesco-primary-endpoint-results-post-marketing.
}

specific attention. In a Swedish study comparing the CV events between AS, RA and the general population, the adjusted RR for stroke was equivalent between AS and RA [1.5 (1.1-2.0) and 1.5 (1.2-1.8), respectively] while there was a smaller increase for acute coronary syndrome in RA than in AS [1.7 (1.4-2.0) and 1.3 (1.0-1.7), respectively]. For thromboembolic events, the risk was also less in AS compared to RA (66). Similar to RA, the increased $\mathrm{CV}$ risk in axSpA may be detected at a preclinical stage using non-invasive techniques (43) (Figure 1). It is well known that inflammation is a major determinant of atheroma development, from plaque initiation to thrombosis. It has been established from epidemiological studies that high sensitivity CRP levels predict CV events in the general population, leading to a higher $\mathrm{CV}$ risk to that induced by $\mathrm{LDL}$ cholesterol during atheroma formation (67). Inflammation in axSpA may be noticed by elevated circulating high sensitivity CRP, interleukin6 or homocysteine (68). The EULAR recommendations for the management of patients with axSpA include the "abrogation of inflammation," highlighting the need to control inflammation to reach this goal (69). The parameters evaluating arterial wall dysfunction in axSpA correlated with disease activity or severity measurements. In addition, it should be stressed that CV risk has mainly been evaluated in the radiographic form of axSpA, whereas limited data exist in nr-axSpA. Recommendations for the $\mathrm{CV}$ risk management in RA have been elaborated by the EULAR group and expanded to axSpA and PsA (70). General principles for the detection and management of $\mathrm{CV}$ diseases in axSpA are outlined, including the correct use of NSAIDs. The identification and subsequent management of traditional CV risk factors is also important. The guidelines recommend the use of risk prediction algorithms, such as SCORE to determine which patients require lipid-lowering and anti-hypertensive therapies. For RA, it is recommended to adjust available prediction scores such as SCORE, by a multiplication factor of 1.5 in order to appropriately evaluate the 10 year CV risk. However, in axSpA, this adjustment is not validated. Lifestyle recommendations include the benefits of a healthy diet, regular exercise and smoking cessation. Physical activity may benefit patients with axSpA, reducing not only $\mathrm{CV}$ risk factors, but also disease activity (71).

\section{CONCLUSION}

Similarly to RA, CV risk is increased in axSpA. This comorbidity is a reality for patients with axSpA and must be adequately evaluated. It is highly probable that the use of bDMARDs (TNFi and probably IL-17i) and specific treatment strategies, such as the treat-to-target paradigm should have a favorable impact on CV risk, and thus, disease prognosis. However, specific clinical studies examining this question are required. Overall, CV risk detection and management is an important aspect for patients with axSpA that deserves specific attention from physicians.

\section{AUTHOR CONTRIBUTIONS}

The author confirms being the sole contributor of this work and has approved it for publication. 


\section{REFERENCES}

1. Sieper J, Poddubnyy D. Axial spondyloarthritis. Lancet. (2017) 390:73-84. doi: 10.1016/S0140-6736(16)31591-4

2. van der Linden S, Valkenburg HA, Cats A. Evaluation of diagnostic criteria for ankylosing spondylitis. a proposal for modification of the New York criteria. Arthritis Rheum. (1984) 27:361-8. doi: 10.1002/art.1780270401

3. Rudwaleit M, van der Heijde D, Landewé R, Listing J, Akkoc N, Brandt J, et al. The development of assessment of spondyloarthritis international society classification criteria for axial spondyloarthritis (part II): validation and final selection. Ann Rheum Dis. (2009) 68:777-83. doi: 10.1136/ard.2009.108233

4. Peters MJ, van der Horst-Bruinsma IE, Dijkmans BA, Nurmohamed MT. Cardiovascular risk profile of patients with spondylarthropathies, particularly ankylosing spondylitis and psoriatic arthritis. Semin Arthritis Rheum. (2004) 34:585-92. doi: 10.1016/j.semarthrit.2004.07.010

5. Moltó A, Nikiphorou E. Comorbidities in spondyloarthritis. Front Med. (2018) 5:62. doi: 10.3389/fmed.2018.00062

6. Avina-Zubieta JA, Thomas J, Sadatsafavi M, Lehman AJ, Lacaille D. Risk of incident cardiovascular events in patients with rheumatoid arthritis: a meta- analysis of observational studies. Ann Rheum Dis. (2012) 71:1524-9. doi: 10.1136/annrheumdis-2011-200726

7. Nurmohamed MT, van der Horst-Bruinsma I, Maksymowych WP. Cardiovascular and cerebrovascular diseases in ankylosing spondylitis: current insights. Curr Rheumatol Rep. (2012) 14:415-21. doi: 10.1007/s11926-012-0270-6

8. Hollan I, Saatvedt K, Almdahl SM, Mikkelsen K, Moer R, Halvorsen P, et al. Spondyloarthritis: a strong predictor of early coronary artery bypass grafting. Scand J Rheumatol. (2008) 37:18-22. doi: 10.1080/03009740701716868

9. Smith PG, Doll R. Mortality among patients with ankylosing spondylitis after a single treatment course with x rays. Br Med J. (1982) 284:449-60. doi: 10.1136/bmj.284.6314.449

10. Carter ET, McKenna CH, Brian DD, Kurland LT. Epidemiology of ankylosing spondylitis in Rochester, Minnesota, 1935-1973. Arthritis Rheum. (1979) 22:365-70. doi: 10.1002/art.1780220408

11. Radford EP, Doll R, Smith PG. Mortality among patients with ankylosing spondylitis not given X-ray therapy. N Engl J Med. (1977) 297:572-6. doi: 10.1056/NEJM197709152971103

12. Kaprove RE, Little AH, Graham DC, Rosen PS. Ankylosing spondylitis: survival in men with and without radiotherapy. Arthritis Rheum. (1980) 23:57-61. doi: 10.1002/art.1780230110

13. Lehtinen K. Mortality and causes of death in 398 patients admitted to hospital with ankylosing spondylitis. Ann Rheum Dis. (1993) 52:174-6. doi: 10.1136/ard.52.3.174

14. Bakland G, Gran JT, Nossent JC. Increased mortality in ankylosing spondylitis is related to disease activity. Ann Rheum Dis. (2011) 70:1921-5. doi: 10.1136/ard.2011.151191

15. Mok CC, Kwok CL, Ho LY, Chan PT, Yip SF. Life expectancy, standardized mortality ratios, and causes of death in six rheumatic diseases in Hong Kong, China. Arthritis Rheum. (2011) 63:1182-9. doi: 10.1002/art.30277

16. Exarchou S, Lie E, Lindström U, Askling J, Forsblad-d'Elia H, Turesson C, et al. Mortality in ankylosing spondylitis: results from a nationwide population-based study. Ann Rheum Dis. (2016) 75:1466-72. doi: 10.1136/annrheumdis-2015-207688

17. Martín-Martínez MA, Castañeda S, Sánchez-Alonso F, García-Gómez C, González- Juanatey C, Sánchez-Costa JT, et al. CARMA Project Collaborative Group Cardiovascular mortality and cardiovascular event rates in patients with inflammatory rheumatic diseases in the CARdiovascular in rheuMAtology (CARMA) prospective study-results at 5 years of follow-up. Rheumatology. (2021) 60:2906-15. doi: 10.1093/rheumatology/keaa737

18. Kim JH, Choi IA. Cardiovascular morbidity and mortality in patients with spondyloarthritis: a meta-analysis. Int J Rheum Dis. (2021) 24:477-86. doi: 10.1111/1756-185X.13970

19. Han C, Robinson DW Jr, Hackett MV, Paramore LC, Fraeman KH, Bala MV. Cardiovascular disease and risk factors in patients with rheumatoid arthritis, psoriatic arthritis, and ankylosing spondylitis. J Rheumatol. (2006) 33:2167-72.

20. Szabo SM, Levy AR, Rao SR, Kirbach SE, Lacaille D, Cifaldi M, et al. Increased risk of cardiovascular and cerebrovascular diseases in individuals with ankylosing spondylitis: a population-based study. Arthritis Rheum (2011) 63:3294-304. doi: 10.1002/art.30581

21. Bengtsson K, Forsblad-d'Elia H, Lie E, Klingberg E, Dehlin M, Exarchou $\mathrm{S}$, et al. Are ankylosing spondylitis, psoriatic arthritis and undifferentiated spondyloarthritis associated with an increased risk of cardiovascular events? a prospective nationwide population-based cohort study. Arthritis Res Ther. (2017) 19:102. doi: 10.1186/s13075-017-1315-Z

22. Brophy S, Cooksey R, Atkinson M, Zhou SM, Husain MJ, Macey S, et al. No increased rate of acute myocardial infarction or stroke among patients with ankylosing spondylitis-a retrospective cohort study using routine data. Semin Arthritis Rheum. (2012) 42:140-5. doi: 10.1016/j.semarthrit.2012. 02.008

23. Mathieu S, Gossec L, Dougados M, Soubrier M. Cardiovascular profile in ankylosing spondylitis: a systematic review and meta-analysis. Arthritis Care Res. (2011) 63:557-63. doi: 10.1002/acr.20364

24. Mathieu S, Pereira B, Soubrier M. Cardiovascular events in ankylosing spondylitis: an updated meta-analysis. Semin Arthritis Rheum. (2015) 44:5515. doi: 10.1016/j.semarthrit.2014.10.007

25. Moltó A, Etcheto A, van der Heijde D, Landewé R, van den Bosch F, Bautista Molano W, et al. Prevalence of comorbidities and evaluation of their screening in spondyloarthritis: results of the international crosssectional ASAS-COMOSPA study. Ann Rheum Dis. (2016) 75:1016-23. doi: 10.1136/annrheumdis-2015-208174

26. González Mazón I, Rueda-Gotor J, Ferraz-Amaro I, Genre F, Corrales A, Calvo Rio V, et al. Subclinical atherosclerotic disease in ankylosing spondylitis and non-radiographic axial spondyloarthritis. a multicenter study on 806 patients. Semin Arthritis Rheum. (2021) 51:395-403. doi: 10.1016/j.semarthrit.2021.02.003

27. Poddubnyy D, Rudwaleit M, Haibel H, Listing J, Märker-Hermann E, Zeidler $\mathrm{H}$, et al. Rates and predictors of radiographic sacroiliitis progression over 2 years in patients with axial spondyloarthritis. Ann Rheum Dis. (2011) 70:1369-74. doi: 10.1136/ard.2010.145995

28. Chung HY, Machado P, van der Heijde D, D'Agostino MA, Dougados M. Smokers in early axial spondyloarthritis have earlier disease onset, more disease activity, inflammation and damage, and poorer function and healthrelated quality of life: results from the DESIR cohort. Ann Rheum Dis. (2012) 7:809-16. doi: 10.1136/annrheumdis-2011-200180

29. Alves MG, Espirito-Santo J, Queiroz MV, Madeira H, Macieira-Coelho E. Cardiac alterations in ankylosing spondylitis. Angiology. (1988) 39: 567-71. doi: $10.1177 / 000331978803900702$

30. Liew JW, Ward MM, Reveille JD, Weisman M, Brown MA, Lee M, et al. Nonsteroidal antiinflammatory drug use and association with incident hypertension in ankylosing spondylitis. Arthritis Care Res. (2020) 72:1645-52. doi: 10.1002/acr.24070

31. Malesci D, Niglio A, Mennillo GA, Buono R, Valentini G, La Montagna. High prevalence of metabolic syndrome in patients with ankylosing spondylitis. Clin Rheumatol. (2007) 26:710-4. doi: 10.1007/s10067-006-0380-5

32. Maas F, Arends S, van der Veer E, Wink F, Efde M, Bootsma H, et al. Obesity is common in axial spondyloarthritis and is associated with poor clinical outcome. J Rheumatol. (2016) 43:383-7. doi: 10.3899/jrheum.150648

33. Toussirot E, Grandclément E, Gaugler B, Michel F, Wendling D, Saas P, et al. Serum adipokines and adipose tissue distribution in rheumatoid arthritis and ankylosing spondylitis. a comparative study. Front Immunol. (2013) 4:453. doi: $10.3389 /$ fimmu.2013.00453

34. Choy E, Ganeshalingam K, Semb AG, Szekanecz Z, Nurmohamed M. Cardiovascular risk in rheumatoid arthritis: recent advances in the understanding of the pivotal role of inflammation, risk predictors and the impact of treatment. Rheumatology. (2014) 53:2143-54. doi: 10.1093/rheumatology/keu224

35. Rössner S. Further studies on serum lipoproteins in connective tissue diseases. Atherosclerosis. (1978) 3:93-9. doi: 10.1016/0021-9150(78)90041-2

36. Joven J, Rubiés-Prat J, Ras MR, de la Figuera M, Lience E, Masdeu S. High density lipoprotein cholesterol subfractions and apoprotein A-I in patients with rheumatoid arthritis and ankylosing spondylitiss. Arthritis Rheum. (1984) 27:1199-200. doi: 10.1002/art.1780271021

37. Papagoras C, Markatseli TE, Saougou I, Alamanos Y, Zikou AK, Voulgari PV, et al. Cardiovascular risk profile in patients with spondyloarthritis. Joint Bone Spine. (2014) 81:57-63. doi: 10.1016/j.jbspin.2013.03.019 
38. Papadakis JA, Sidiropoulos PI, Karvounaris SA, Vrentzos GE, Spanakis EK, Ganotakis ES, et al. High prevalence of metabolic syndrome and cardiovascular risk factors in men with ankylosing spondylitis on antiTNFalpha treatment: correlation with disease activity. Clin Exp Rheumatol. (2009) 27:292-8.

39. Semb AG, Kvien TK, DeMicco DA, Fayyad R, Wun CC, LaRosa J, et al. Prediction of cardiovascular events in patients with ankylosing spondylitis and psoriatic arthritis: role of lipoproteins in a high-risk population. $J$ Rheumatol. (2012) 39:1433-40. doi: 10.3899/jrheum.111307

40. Tyrrell PN, Beyene J, Feldman BM, McCrindle BW, Silverman ED, Bradley TJ. Rheumatic disease and carotid intima-media thickness: a systematic review and meta-analysis. Arterioscler Thromb Vasc Biol. (2010) 30:1014-26. doi: 10.1161/ATVBAHA.109.198424

41. Arida A, Protogerou AD, Konstantonis G, Konsta M, Delicha EM, Kitas GD, et al. Subclinical atherosclerosis is not accelerated in patients with ankylosing spondylitis with low disease activity: new data and metaanalysis of published studies. J Rheumatol. (2015) 42:2098-105. doi: 10.3899/jrheum. 150316

42. Bai R, Zhang Y, Liu W, Ma C, Chen X, Yang J, et al. The relationship of ankylosing spondylitis and subclinical atherosclerosis: a systemic review and meta-analysis. Angiology. (2019) 70:492-500. doi: 10.1177/0003319718814309

43. Gonzalez-Juanatey C, Vazquez-Rodriguez TR, Miranda-Filloy JA, Dierssen $\mathrm{T}$, Vaqueiro I, Blanco $\mathrm{R}$, et al. The high prevalence of subclinical atherosclerosis in patients with ankylosing spondylitis without clinically evident cardiovascular disease. Medicine. (2009) 88:358-65. doi: 10.1097/MD.0b013e3181c10773

44. Bodnár N, Kerekes G, Seres I, Paragh G, Kappelmayer J, Némethné ZG, et al. Assessment of subclinical vascular disease associated with ankylosing spondylitis. J Rheumatol. (2011) 38:723-9. doi: 10.3899/jrheum.100668

45. Choi HK, Hernán MA, Seeger JD, Robins JM, Wolfe F. Methotrexate and mortality in patients with rheumatoid arthritis: a prospective study. Lancet. (2002) 359:1173-7. doi: 10.1016/S0140-6736(02)08213-2

46. Coxib and traditional NSAID Trialists' (CNT) Collaboration, Bhala N, Emberson J, Merhi A, Abramson S, Arber N, et al. Vascular and upper gastrointestinal effects of non-steroidal anti-inflammatory drugs: metaanalyses of individual participant data from randomised trials. Lancet. (2013) 382:769-79. doi: 10.1016/S0140-6736(13)60900-9

47. Haroon NN, Paterson JM, Li P, Inman RD, Haroon N. Patients with ankylosing spondylitis have increased cardiovascular and cerebrovascular mortality: a population-based study. Ann Intern Med. (2015) 163:409-16. doi: 10.7326/M14-2470

48. Tam HW, Yeo KJ, Leong PY, Chen CH, Li YC, Ma CM, et al. Sulfasalazine might reduce risk of cardiovascular diseases in patients with ankylosing spondylitis: a nationwide population-based retrospective cohort study. Int $J$ Rheum Dis. (2017) 20:363-70. doi: 10.1111/1756-185X.12986

49. Roubille C, Richer V, Starnino T, McCourt C, McFarlane A, Fleming P et al. The effects of tumour necrosis factor inhibitors, methotrexate, nonsteroidal anti-inflammatory drugs and corticosteroids on cardiovascular events in rheumatoid arthritis, psoriasis and psoriatic arthritis: a systematic review and meta-analysis. Ann Rheum Dis. (2015) 74:480-9. doi: 10.1136/annrheumdis-2014-206624

50. Deyab G, Hokstad I, Whist JE, Smastuen MC, Agewall S, Lyberg T et al. Methotrexate and anti-tumor necrosis factor treatment improves endothelial function in patients with inflammatory arthritis. Arthritis Res Ther. (2017) 19:232. doi: 10.1186/s13075-017-1439-1

51. van Sijl AM, van Eijk IC, Peters MJ, Serné EH, van der Horst-Bruinsma IE, Smulders YM, et al. Tumour necrosis factor blocking agents and progression of subclinical atherosclerosis in patients with ankylosing spondylitis. Ann Rheum Dis. (2015) 74:119-23. doi: 10.1136/annrheumdis-2013-2 03934

52. Genre F, López-Mejías R, Miranda-Filloy JA, Ubilla B, Mijares V. CarneroLópez B et al. Anti-TNF- $\alpha$ therapy reduces endothelial cell activation in nondiabetic ankylosing spondylitis patients Rheumatol Int. (2015) 35:2069-78. doi: 10.1007/s00296-015-3314-1

53. Tam LS, Kitas GD, González-Gay MA. Can suppression of inflammation by anti-TNF prevent progression of subclinical atherosclerosis in inflammatory arthritis? Rheumatology. (2014) 53:1108-19. doi: 10.1093/rheumatology/ket454
54. Kiortsis DN, Mavridis AK, Filippatos TD, Vasakos S, Nikas SN, Drosos AA. Effects of infliximab treatment on lipoprotein profile in patients with rheumatoid arthritis and ankylosing spondylitis. J Rheumatol. (2006) 33:9213.

55. van Eijk IC, de Vries MK, Levels JH, Peters MJ, Huizer EE, Dijkmans BA, et al. Improvement of lipid profile is accompanied by atheroprotective alterations in high-density lipoprotein composition upon tumor necrosis factor blockade: a prospective cohort study in ankylosing spondylitis. Arthritis Rheum. (2009) 60:1324-30. doi: 10.1002/art.24492

56. Toussirot É, Mourot L, Dehecq B, Wendling D, Grandclément É, Dumoulin $\mathrm{G}$, et al. TNF $\alpha$ blockade for inflammatory rheumatic diseases is associated with a significant gain in android fat mass and has varying effects on adipokines: a 2-year prospective study. Eur J Nutr. (2014) 53:951-61. doi: 10.1007/s00394-013-0599-2

57. Robert M, Miossec P. Effects of interleukin 17 on the cardiovascular system. Autoimmun Rev. (2017) 16:984-91. doi: 10.1016/j.autrev.2017.07.009

58. Baeten D, Sieper J, Braun J, Baraliakos X, Dougados M. Emery P, et al. Secukinumab, an Interleukin-17A Inhibitor, in Ankylosing Spondylitis. N Engl J Med. (2015) 373:2534-48. doi: 10.1056/NEJMoa1505066

59. Dougados M, Wei JC, Landewé R, Sieper J, Baraliakos X, Van den Bosch F, et al. COAST-V and COAST-W Study Groups. Efficacy and safety of ixekizumab through 52 weeks in two phase 3, randomised, controlled clinical trials in patients with active radiographic axial spondyloarthritis (COAST-V and COAST-W). Ann Rheum Dis. (2020) 79:176-85. doi: 10.1136/annrheumdis-2019-216118

60. Rungapiromnan W, Yiu ZZN, Warren RB, Griffiths CEM, Ashcroft DM. Impact of biologic therapies on risk of major adverse cardiovascular events in patients with psoriasis: systematic review and meta-analysis of randomized controlled trials. Br J Dermatol. (2017) 176:890-901. doi: 10.1111/bjd.14964

61. van de Kerkhof PC, Griffiths CE, Reich K, Leonardi CL, Blauvelt A, Tsai TF, et al. Secukinumab long-term safety experience: a pooled analysis of 10 phase II and III clinical studies in patients with moderate to severe plaque psoriasis. J Am Acad Dermatol. (2016) 75:83-98. doi: 10.1016/j.jaad.2016.03.024

62. Genovese MC, Mysler E, Tomita T, Papp KA, Salvarani C, Schwartzman $S$, et al. Safety of ixekizumab in adult patients with plaque psoriasis, psoriatic arthritis and axial spondyloarthritis: data from 21 clinical trials. Rheumatology. (2020) 59:3834-44. doi: 10.1093/rheumatology/keaa189

63. Poddubnyy D, Sieper J. Treatment of axial spondyloarthritis: what does the future hold? Curr Rheumatol Rep. (2020) 22:47. doi: 10.1007/s11926-020-00924-5

64. Xie W, Huang Y, Xiao S, Sun X, Fan Y, Zhang Z. Impact of Janus kinase inhibitors on risk of cardiovascular events in patients with rheumatoid arthritis: systematic review and meta-analysis of randomised controlled trials. Ann Rheum Dis. (2019) 78:1048-54. doi: 10.1136/annrheumdis-2018-214846

65. Mease P, Charles-Schoeman C, Cohen S, Fallon L, Woolcott J, Yun H, et al. Incidence of venous and arterial thromboembolic events reported in the tofacitinib rheumatoid arthritis, psoriasis and psoriatic arthritis development programmes and from real-world data. Ann Rheum Dis. (2020) 79:1400-13. doi: 10.1136/annrheumdis-2019-216761

66. Eriksson JK, Jacobsson L, Bengtsson K, Askling J. Is ankylosing spondylitis a risk factor for cardiovascular disease, and how do these risks compare with those in rheumatoid arthritis? Ann Rheum Dis. (2017) 72:364-70. doi: 10.1136/annrheumdis-2016-209315

67. Ridker PM. From C-Reactive protein to interleukin-6 to interleukin1: moving upstream to identify novel targets for atheroprotection. Circ Res. (2016) 118:145-56. doi: 10.1161/CIRCRESAHA.115. 306656

68. Divecha H, Sattar N, Rumley A, Cherry L, Lowe GD, Sturrock R. Cardiovascular risk parameters in men with ankylosing spondylitis in comparison with non-inflammatory control subjects: relevance of systemic inflammation. Clin Sci. (2005) 109:171-6. doi: 10.1042/CS200 40326

69. van der Heijde D, Ramiro S, Landewé R, Baraliakos X, Van den Bosch F, Sepriano A, et al. 2016 update of the ASAS-EULAR management recommendations for axial spondyloarthritis. Ann Rheum Dis. (2017) 76:97899. doi: 10.1136/annrheumdis-2016-210770

70. Agca R, Heslinga SC, Rollefstad S, Heslinga M, McInnes IB, Peters MJ, et al. EULAR recommendations for cardiovascular disease risk management 
in patients with rheumatoid arthritis and other forms of inflammatory joint disorders: 2015/2016 update. Ann Rheum Dis. (2017) 76:17-28. doi: 10.1136/annrheumdis-2016-209775

71. Sveaas SH, Berg IJ, Provan SA, Semb AG, Hagen KB, Vøllestad N, et al. Efficacy of high intensity exercise on disease activity and cardiovascular risk in active axial spondyloarthritis: a randomized controlled pilot study. PLoS ONE. (2014) 9:e108688. doi: 10.1371/journal.pone.010 8688

Conflict of Interest: The author declares that the research was conducted in the absence of any commercial or financial relationships that could be construed as a potential conflict of interest.
Publisher's Note: All claims expressed in this article are solely those of the authors and do not necessarily represent those of their affiliated organizations, or those of the publisher, the editors and the reviewers. Any product that may be evaluated in this article, or claim that may be made by its manufacturer, is not guaranteed or endorsed by the publisher.

Copyright $\odot 2021$ Toussirot. This is an open-access article distributed under the terms of the Creative Commons Attribution License (CC BY). The use, distribution or reproduction in other forums is permitted, provided the original author(s) and the copyright owner(s) are credited and that the original publication in this journal is cited, in accordance with accepted academic practice. No use, distribution or reproduction is permitted which does not comply with these terms. 